\title{
As conceções dos pais sobre o educador de infância em contexto hospitalar
}

\author{
Maria Serrão, Carolina Carvalho \\ Instituto de Educação Universidade de Lisboa
}

\begin{abstract}
Resumo
O educador de infância ao exercer a sua ação educativa num contexto diferente da escola constrói uma identidade específica ajustada à realidade do meio onde ocorre a sua prática pedagógica. O presente artigo refere-se à prática do educador de infância em contexto hospitalar, enquadrando-se numa investigação mais abrangente desenvolvida no Serviço de Pediatria de dois Hospitais, um numa Região Autónoma e o outro na Região de Lisboa. O objetivo principal é conhecer a importância atribuída pelos pais/acompanhantes à presença do educador de infância no Serviço de Pediatria. O instrumento utilizado foi o questionário e os participantes foram 174 pais/acompanhantes com crianças internadas. A metodologia de investigação do estudo assentou no paradigma interpretativo e numa abordagem qualitativa.
\end{abstract}

Palavras-chave: família, prática do educador de infância, criança, internamento

O estudo agora apresentado é o resultado de uma investigação mais ampla desenvolvida no Serviço de Pediatria de dois hospitais públicos portugueses.

$\mathrm{Na}$ realização deste estudo optou-se por uma metodologia de natureza qualitativa. Uma investigação com esta natureza tem uma abordagem complexa e "exige que o mundo seja examinado com a ideia de que nada é trivial, que tudo tem potencial para construir uma pista que nos permita estabelecer uma compreensão mais esclarecedora do nosso objeto de estudo” (Bogdan \& Biklen, 1994, p. 49).

Com os questionários direcionados aos pais/acompanhantes pretendeu-se conhecer as necessidades, durante o internamento e após a alta da criança e as conceções sobre o educador de infância em contexto hospitalar.

\section{Participantes}

Os participantes do estudo foram 174 pais/acompanhantes com crianças internadas, no Serviço de Pediatria. Dos 174 pais/acompanhantes inquiridos 141 são mães, 25 são pais e 7 são avós.

Nas suas respostas os pais/acompanhantes depositam confiança no educador de infância que lhes suscita o sentimento de segurança e de acolhimento, de modo a minimizar as inquietações das crianças, durante o período de internamento, através de práticas didático-pedagógicas adequadas aos seus interesses e às necessidades específicas de cada criança.

\section{Instrumento e Materiais}

O questionário utilizado foi inspirado no Needs of Parents Questionaire (NPQ) desenvolvido por Gudrún Kristjànsdóttir (1986; 1998). Este questionário tem uma adaptação para Portugal realizada por Ferreira, Melo e Reis (2005).Concretamente no presente trabalho foram introduzidos itens de forma a conseguir recolher informações referentes às necessidades sentidas pelos pais/acompanhantes durante e após o internamento da criança, bem como a sua opinião sobre o educador em contexto hospitalar.

O questionário usado está dividido em três partes. Na primeira parte pretendeu-se recolher informações para efeitos de contextualização sobre as crianças e os pais/acompanhantes: a idade dos pais/acompanhantes da criança (Questão 1); o grau de parentesco (Questão 2); as habilitações dos pais/acompanhantes (Questão 3); o estado civil (Questão 4); a idade da criança (Questão 5); duração de hospitalização (Questão 6); a gravidade da doença (Questão 7); o tipo de doença (Questão 8); se o internamento foi planeado/não planeado (Questão 9); a experiência de internamento (Questão 10); e, o número de filhos (Questão 11).

$\mathrm{Na}$ segunda parte pretendeu-se conhecer as necessidades dos pais/acompanhantes, no Serviço de Pediatria, através de 16 Itens, da Questão 12. Os itens sobre as necessidades dos pais/acompanhantes, os quais foram selecionados em função do tipo de necessidades, tipificadas em outros trabalhos, onde "foram categorizadas de acordo com Gudrún Kristjànsdóttir, em diferentes tipos de necessidades" (Reis, 2007, p. 64), tais como: Necessidade de Sentir que Confiam em Si; Necessidade de Informação; Necessidade de Suporte e Orientação; Necessidades relativas a Recursos Físicos e Humanos.

Na Questão 13 pretendeu-se conhecer se a presença do educador de infância é importante no Serviço de Pediatria, utilizando uma escala dicotómica: Sim ou Não. Por sua vez, com a questão aberta 14 pretendeu-se obter informação sobre a importância atribuída ao educador de infância no Serviço de Pediatria.

Na terceira parte pretendeu-se conhecer as conceções dos pais/acompanhantes sobre a prática do educador de infância em contexto hospitalar, com a Questão 15 através de uma bateria de 12 itens. 
Contudo no presente artigo tratou-se somente sobre a importância atribuída à presença do educador de infância, no Serviço de Pediatria, através de uma questão aberta, recorrendo à análise de conteúdo.

\section{Procedimento}

No estudo, tendo em conta a natureza e a dimensão do trabalho, antes de proceder à recolha de dados, fez-se o pedido formal às Comissões de Ética para realizar a investigação, cujo pedido foi aceite pelos dois hospitais.

$\mathrm{Na}$ entrega dos questionários aos pais/acompanhantes foi entregue uma folha de rosto a informar o objetivo do estudo e o que se pretendia com a investigação no Serviço de Pediatria, cujo objetivo era ter o seu consentimento informado

Os questionários foram entregues e recolhidos pelas educadoras de infância que trabalham nos Serviços de Pediatria. Os questionários foram aplicados em dois Hospitais: um numa Região Autónoma (Hospital A) e outro na Região de Lisboa (Hospital B).

No Hospital A o questionário foi aplicado em períodos distintos, com um intervalo de um mês entre julho 2012 e fevereiro de 2013. Por sua vez, no Hospital B os questionários foram aplicados, entre setembro de 2013 a fevereiro de 2014.

\section{Resultados}

No presente artigo apenas se vai considerar a resposta aberta dos pais/acompanhantes à questão: Na sua opinião a presença do educador de infância é importante no Serviço de Pediatria: Sim ou Não. Caso a sua resposta tenha sido Sim diga porquê.

As categorias de análise que emergiram dos questionários e que seguidamente se apresentam ilustram alguns exemplos de cada categoria identificada.

Estas categorias da análise indutiva de conteúdo vão ao encontro das linhas de orientação de Estrela (1994) quando defende que “à semelhança do que acontece em qualquer processo de categorização, a determinação das categorias deverá obedecer a critérios de coerência, homogeneidade, exclusividade recíproca e exaustividade” (p. 456). Também, para Bardin (2009) “a categorização é uma classificação de elementos constitutivos de um conjunto por diferenciação e, seguidamente, por reagrupamento segundo o género (analogia), com os critérios previamente definidos” (p. 145).

Dos 174 pais/acompanhantes inquiridos 26 não responderam à questão aberta. Na análise enumerámos 245 registos no universo das respostas dadas, perfazendo 148 registos repartidos por nove categorias. A análise de conteúdo das respostas à questão aberta, relativamente à opinião dos pais/acompanhantes sobre a importância atribuída à presença do educador de infância no Serviço de Pediatria, foi feita a partir das seguintes categorias, a saber: Categoria 1 Ajuda no internamento; Categoria 2 Ajuda a ocupar o tempo; Categoria 3 Ajuda os pais; Categoria 4 Promove atividades lúdicas; Categoria 5

Promove o bem-estar; Categoria 6 Promove a socialização; Categoria 7 Ajuda a motivar; Categoria 8 Promove o desenvolvimento e a aprendizagem; e, Categoria 9 Outras definições.

Nas nove categorias resultantes da análise de conteúdo constata-se que $15.5 \%$ dos pais/acompanhantes referem que a presença do educador de infância, no Serviço de Pediatria, ajuda a criança a aceitar, a esquecer e a continuar as suas rotinas durante o internamento (Categoria 1 - Ajuda no Internamento). Dos pais/acompanhantes inquiridos $15.9 \%$ afirmam que a presença do educador de infância permite que a criança se abstraia do processo de internamento, ajudando a ocupar o tempo (Categoria 2 - Ajuda a ocupar o tempo). Existem 3.3\% pais/acompanhantes que referem que a presença do educador de infância é ponderada como um apoio acrescido, atendendo que a criança tem alguém que lhe faça companhia na sua ausência (Categoria 3 - Ajuda os pais). Em relação à Categoria 4, 14.7\% dos pais/acompanhantes revelam que o educador de infância promove momentos lúdicos, permitindo à criança entretenimento, brincadeira, distração e ânimo, durante o período de internamento (Categoria 4 - Promove atividades lúdicas). $\mathrm{Na}$ Categoria $5, \quad 14.3 \%$ dos pais/acompanhantes a presença do educador de infância ajuda a criança a diminuir o medo, o isolamento, a depressão, a dor, o cansaço e o sofrimento, advindos do internamento, trazendo efeitos benéficos ao nível do seu bem-estar (Categoria 5 - Promove o bem-estar). Em relação à Categoria 6, 4.9\% dos pais/acompanhantes opinam que a presença do educador de infância promove momentos de convívio e de interações sociais entre crianças e adultos (Categoria 6 - Promove $a$ socialização). Constata-se, ainda, que $6.1 \%$ dos pais/acompanhantes referem que a presença do educador de infância mantem a criança motivada, durante o internamento, nas suas rotinas e nos tratamentos (Categoria 7 - Ajuda a motivar).Para 22.0\% dos pais/acompanhantes a presença do educador de infância, no Serviço de Pediatria, permite a continuidade do processo de ensino e de aprendizagem das crianças, através da sua prática pedagógica (Categoria 8 - Promove o desenvolvimento e a aprendizagem). E, por último, constata-se que 3.3\% dos pais/acompanhantes atribuem relevância à presença do educador de infância no Serviço de Pediatria, recorrendo a dimensões mais difusas e que foram agrupadas na Categoria 9, Outras definições (ver Figura 1).

60

50

50
40

30

30
20

20
10

10
0

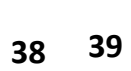

$38 \quad 39$

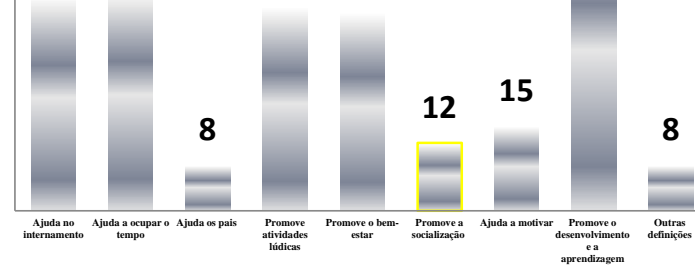

Figura 1. Importância do educador de infância 
Na Categoria 1, ajuda no internamento, constata-se que o educador de infância ajuda no internamento da criança. Para os pais/acompanhantes o educador de infância no Serviço de Pediatria é um profissional de educação que através de práticas assertivas interpreta e intervém mediante as necessidades e os interesses de cada criança, ajudando-a no seu internamento. Além disso, "o educador de infância ajuda também as crianças a ultrapassarem a sua passagem pelo Serviço de Pediatria” (Q32) e, ainda, "porque a criança não fica aborrecida e dá mais segurança” (Q1). No âmbito da subcategoria esquecer os pais/acompanhantes referem que o educador de infância "ajuda a criança a esquecer durante momentos que está hospitalizada” (Q39). Para outro pai/acompanhante estes profissionais de educação “ajudam a esquecer a hospitalização” (Q134).

Na Categoria 2, ajuda a ocupar o tempo, os pais/acompanhantes afirmam que face às necessidades das crianças a realização de atividades lúdicas e pedagógicas contribuem para a ocupação dos seus tempos livres. A presença do educador de infância é valorizada por alguns pais/acompanhantes, atendendo que "a criança sente que tem alguém além da mãe para lhe ajudar a passar o tempo" (Q30) e “é sem dúvida uma presença muito importante, pois ajuda muito que a criança se sinta ocupada” (Q167). Trata-se de uma presença importante para a criança porque serve "para ocupar o tempo que está internada” (Q136).

$\mathrm{Na}$ Categoria 3, ajuda os pais/acompanhantes, constata-se que os pais/acompanhantes reconhecem que o educador de infância desempenha uma função de apoio à família, aquando da sua ausência no Serviço de Pediatria. Nesta categoria a presença do educador de infância está associada ao sentimento de confiança e de segurança, permitindo aos pais e/ou à família se ausentarem por algum tempo do Serviço de Pediatria. Para alguns pais/acompanhantes o educador de infância é considerado, ainda, como "uma companhia” (Q34, Q160), um “bom apoio” (Q35), ajuda a criança a "aliviar um pouco o cansaço” (Q47).

Na Categoria 4, promove atividades lúdicas, para os pais/acompanhantes a realização de atividades lúdicas ajuda a prevenir danos emocionais e psicológicos, advindos do internamento. A realização de atividades lúdicas é, mais do que um instrumento de entretenimento, um meio de excelência "para as crianças continuarem a brincar mesmo estando em ambiente hospitalar” (Q111) e, por sua vez, estes momentos são convertidos em momentos de animação e de brincadeira e servem “para animarem as crianças” (Q165).

$\mathrm{Na}$ Categoria 5, promove o bem-estar, para os pais/acompanhantes a prática do educador de infância sustentada em vínculos afetivos faz com que a criança se adapte melhor ao novo meio onde está inserida, neste caso ao contexto hospitalar. Os pais/acompanhantes atribuem relevância educador de infância, dizendo que a sua presença no Serviço de Pediatria "ajuda a perder o medo do hospital” (Q23) e “a minimizar o medo do desconhecido (o internamento)” (Q82). Constata-se, ainda, que a presença do educador de infância "ajuda a promover uma sensação de maior competência e um ambiente menos depressivo” (Q116) e, sobretudo, “para os meninos não se isolarem no quarto e ficarem tristes e aborrecidos” (Q170). Há, também, outros pais/acompanhantes que o educador de infância ajuda otimizar o internamento, como ilustram os exemplos que se seguem: "Perante situações de dor, atividade como aquelas que são feitas são sem dúvida muito importantes para que as crianças esqueçam as situações, por vezes, traumatizantes” (Q8); “Aliviam a sua dor” (Q71); “As crianças ficam cansadas e amedrontadas com a doença (...) a dor é um factor constante” (Q146).

Na Categoria 6, promove a socialização, a prática do educador de infância torna-se crucial para os pais/acompanhantes, atendendo que são considerados como agentes promotores de espaços de convivência e de diálogo entre crianças e adultos. A valorização das interações sociais entre crianças prevalece nos discursos dos pais/acompanhantes, como se pode observar nos seguintes exemplos: "Para que as crianças se relacionem umas com as outras” (Q31); “Ajuda a criança a conviver com outras" (Q39); "Para interagir com os outros meninos” (Q170).

$\mathrm{Na}$ Categoria 7, ajuda a motivar, os pais/acompanhantes responderam que o educador de infância, no Serviço de Pediatria, "motiva a criança, ajudando-a divertir-se e a distrair-se sem precisar de pensar no seu problema de saúde” (Q84) e, além disso, “é uma boa maneira de motivar e animar as crianças durante a sua reabilitação” (Q85). Nestes exemplos constata-se que a motivação da criança durante o internamento está relacionada com o empenho da intervenção do educador de infância, através de abordagens ajustadas às necessidades específicas e aos interesses das crianças. Para outros pais/acompanhantes o educador de infância, no Serviço de Pediatria, "motiva a criança, ajudando-a divertir-se e a distrair-se sem precisar de pensar no seu problema de saúde" (Q84) e, além disso, “é uma boa maneira de motivar e animar as crianças durante a sua reabilitação” (Q85). Nestes dois exemplos constata-se que a motivação da criança durante o internamento está relacionada com o empenho da intervenção do educador de infância, através de abordagens ajustadas às necessidades específicas e aos interesses das crianças.

No entanto outros pais/acompanhantes consideram que o educador de infância recorre a outras estratégias adequadas aos problemas motivacionais da criança, de maneira a que criança esteja "motivada em atividades que ocupam a sua mente” (Q114), ou seja, "porque as motiva bastante a lidar com seu internamento e a mantê-las no ativo” (Q108). Trata-se de uma presença que "ajuda acrescer a motivação na criança e melhora a actividade física e psíquica fora do âmbito médico" (Q124). Existem, ainda, pais/acompanhantes que consideram "importante a presença do educador para ajudar a motivar" (Q140) e "para manter a criança motivada” (Q152, Q160).

Na Categoria 8, promove o desenvolvimento e a aprendizagem, para os pais/acompanhantes a existência do educador permite a continuidade do processo de ensino e de aprendizagem da criança durante o internamento. Importa realçar que os pais/acompanhantes atribuíram maior relevância a esta categoria, com 56 respostas. Esta categoria está 
associada às subcategorias estimulação, participação nas atividade e aprendizagens e desenvolvimento.

Na subcategoria estimulação consta-se que a presença do educador de infância "serve como elo de ligação entre a equipa médica” (Q50) e, ainda, "para poder continuar a desenvolver competências pedagógicas das crianças internadas, uma vez que estas foram interrompidas devido ao internamento" (Q56).

Os pais/acompanhantes sentem a necessidade que as crianças tenham oportunidades de aprendizagem significativas e que lhes sejam dadas oportunidades para enriquecer a sua experiência curricular, mesmo durante o período de internamento. Ou seja, a presença do educador de infância é valorizada pelos pais/acompanhantes, com crianças mais velhas que frequentam outros níveis de ensino, permitindo que "durante o internamento não haja perda de matéria e ritmo de estudo adquirido antes do internamento (Q129) e, efetivamente, "a presença do educador de infância é importante, para estimular actividades nas crianças” (Q170).

$\mathrm{Na}$ subcategoria participação nas atividades os pais/acompanhantes atribuem relevância à participação das crianças nas atividades realizadas pelo educador de infância, como ilustram os exemplos que se seguem: "Para não sentirem a falta das actividades escolares e professores” (Q36); "Para que a criança possa continuar com as actividades de aprendizagem” (Q37); "Porque as crianças podem ter actividades que promovem o desenvolvimento" (Q168); "Parece-me importante a presença de uma educadora para que a criança possa ser estimulada com atividades planeadas/programadas" (Q166). Refira-se neste conjunto de exemplos, constata-se que os pais/acompanhantes sublinham que a participação das crianças nas atividades reflete-se na continuidade das suas aprendizagens escolares e no seu processo de desenvolvimento.

Para alguns pais/acompanhantes o educador de infância desenvolve "competências pedagógicas” (Q56) e a continuidade de "atividades educativas" com uma intencionalidade educativa (Q36, Q37, Q47, Q166, Q170), em prol do desenvolvimento holístico da criança, mesmo encontrando-se fora do seu ambiente escolar, neste caso em contexto hospitalar.

Algumas das respostas dos pais/acompanhantes da questão aberta foram agrupadas na Categoria 9, outras definições, atendendo que estas não se plasmavam nas categorias anteriormente descritas, eis alguns exemplos: "Na minha opinião deveriam estar também presentes aos fins-de-semanas" (Q82); “É muito bom ter uma educadora na enfermaria (Q157); “Sim, é importante ter uma educadora” (Q174). Há outro pai/acompanhante que exalta a importância da presença do educador, no Serviço de Pediatria, "obrigada por existir aqui o educador!” (Q131). Estes exemplos espelham a importância atribuída ao educador de infância no acolhimento e na adaptação da criança em contexto hospitalar, bem como a importância da sua permanência todos os dias no Serviço de Pediatria, inclusive aos fins-de-semana, integrados numa equipa de saúde, através dos verbos estar, existir e ter.

\section{Discussão}

Com os resultados obtidos constata-se que os pais/acompanhantes inquiridos revelam que o educador de infância é um profissional capaz de enfrentar novos desafios que vão além da sua prática pedagógica no ensino regular, conforme é plasmado na legislação e nos objetivos definidos pela Tutela. Ou seja, estes profissionais são capazes de adaptar a sua prática a um contexto diferente do que habitualmente existe numa sala de aula.

No contexto hospitalar, a rotatividade das crianças trazidas pelo próprio internamento dita ao educador uma grande adaptabilidade de planeamento e de rotinas comuns num contexto de sala de aula em jardim-de-infância.

Para os pais/acompanhantes o educador de infância revela-se como um profissional de educação, cuja prática em contexto hospitalar abrange conhecimentos complexos de natureza multidimensional e multifacetada, apesar de possuir formação inicial na educação de infância.

Ante os resultados o educador de infância promove na criança aprendizagens significativas e diversificadas, recorrendo a estratégias e a atividades de acordo com os interesses e as necessidades reais de cada caso clínico, contribuindo para manter o processo de ensino e de aprendizagem das crianças.

Para os pais/acompanhantes o educador de infância assume o papel de alicerce no bem-estar social e emocional das crianças e das suas famílias, promovendo a sua integração no Serviço de Pediatria, facilitando a transição para níveis posteriores no seu processo de ensino e de aprendizagem quando voltar ao jardim de infância ou à escola.

\section{Referências}

Bardin, L. (2009). Análise de conteúdo. (L. A. Reto \& A. Pinheiro, Trads.). Lisboa: Edições 70, Lda.

Bogdan, R. \& Biklen, S. (1994). Investigação qualitativa em educação: uma introdução à teoria e aos métodos. Porto: Porto Editora.

Estrela, A. (1994). Teoria e prática de observações de classes: uma estratégia de formação de professores. (4 $4^{\text {a }}$ ed.). Lisboa: Instituto Nacional de Investigação Científica.

Ferreira, P., Reis G. \& Melo E. (2005). Questionário sobre as Necessidades dos Pais. Coimbra: Centro de Estudos de Investigação na Saúde da Faculdade de Economia da Universidade de Coimbra. 